\title{
Los vacíos de la política en época de globalización. Z. Bauman ¿versus? J. Habermas
}

\author{
The Vacuums of Politics in Times of Globalization. \\ Z. Bauman ¿versus? J. Habermas \\ ROSA JIMÉNEZ ASENSIO \\ I.E.S. «Arturo Soria», Madrid
}

\begin{abstract}
RESUMEN. Este trabajo aborda la situación en la que se encuentra el vínculo político en el momento presente de «globalización» desde la perspectiva de Habermas y Bauman, viendo los puntos que tienen en común y sus divergencias, a partir de su origen en la Teoría Crítica. Desde una interpretación diferente de la Modernidad, analizan los elementos en los que se centra la crisis de lo político en la actualidad: el desplazamiento del Estado como organizador social, y el vaciamiento de la esfera pública - colonizada por lo sistémico o privatizada-, así como la ausencia de sentimientos de vinculación solidaria, que generan una sociedad individualizada en la que está ausente todo atisbo de pensamiento emancipador.
\end{abstract}

Palabras clave: Modernidad, Habermas, Bauman, público/privado, esfera pública,
ABSTRACT. This work deals with the problem of where the political link is at the present time of globalization from the perspective of Habermas and Bauman, looking at the points they have in common and at their differences, from their origins in Critical Theory. From a different interpretation of Modernity, they analyze the elements in which the current crisis of politics is focused: the displacement of the State as social organizer, and the vacuousness of the public sphere (colonized by the systemic, or privatized) as well as the lack of solidarity feelings, generating an individualistic society lacking any sign of emancipating thought.

Key words: Modernity, Habermas, Bauman, public/private, public sphere.

Cuando hablamos de «vacíos de la política» nos referimos a un determinado escenario que condensa la posición de la sociedad en el presente. Esta situación viene marcada principalmente por el dominio de una concepción de la política puramente instrumental que deja fuera de sí (en cuanto a representación y cognoscibilidad) el elemento fundamental de la misma: su sentido fundante de comunidad, o dicho en los términos que utiliza Claude Lefort, el sentido de «lo político».

Lo «político», a diferencia de «la política» remite a la forma en que se articula el ser común. Es lo que hace legible la articulación de las distintas par- 
tes de la sociedad y las relaciones entre los grupos, así como sus prácticas, actividades y representaciones. No se trata de concebir la sociedad como una totalidad (cosa completamente imposible) sino de buscar y captar el «principio de interiorización que dé razón de un modo singular de diferenciación y de relación de las clases, de los grupos o de las condiciones y, simultáneamente, de un modo singular de discriminación de las referencias en función de las cuales se ordena la experiencia de la coexistencia - referencias económicas, jurídicas, estéticas, religiosas...» ${ }^{1}$.

Este principio de interiorización es el que posibilita la «puesta en escena» (representación) de las forma de coexistencia humana desde su constitución originariamente política. La forma en que se organiza una sociedad da cuenta de su misma institución como un régimen determinado, como una manera de «darse en el mundo», de las formas de diferenciación y de las condiciones de ésta que sanciona. No se puede, como indica el mismo Lefort, establecer una divisoria entre lo que sea del orden político, económico, jurídico, o religioso, sino es desde una experiencia originaria de un modo de institución de lo social en el que son aprehensibles tales divisorias, pues al hacerlas estamos ya inscritos en una determinada forma de experiencia, tenemos detrás nuestro la idea de una dimensionalidad de lo social. De ahí la radicalidad del pensar sobre lo político que aboca al problema del vínculo social, de la forma de representación de una sociedad sobre sí misma, de lo que puede o no ser representado, de lo que manifiesta u oculta.

Con estos presupuestos sobre lo político ${ }^{2}$ se hace el abordaje de los riesgos de descomposición del vínculo social moderno que parece darse en las últimas décadas y que encuadramos bajo la denominación general de «globalización», «mundialización» o cualquier sinónimo al uso ${ }^{3}$. De una forma o de otra, éste el nombre con el que venimos designando el presente, y como toda denominación onmiabarcante, y manoseada mediáticamente, termina por no denotar nada ${ }^{4} \mathrm{y}$ cada cual lo utiliza según el momento y el interés. En nuestro contexto de análisis, la globalización se refiere a lo que Marramao denomina la «erosión de la soberanía» ${ }^{5}$, a la pérdida del poder soberano de su capacidad estructurante de

1 Lefort, C., La incertidumbre democrática, Barcelona, Anthopos, 2004, p. 59.

2 También se ha desarrollado la dicotomía político/política desde la diferenciación entre el carácter fundantemente conflictivo de lo social (lo político) y el intento de domeñarlo desde una perspectiva de orden (la política), dando lugar a una fructífera corriente sobre la democracia radical de tintes agonistas expuesta principalmente en las obras de Chantal Mouffe y Ernesto Laclau, Hegemonía y estrategia socialista, Buenos Aires, FCE, 2004, y por separado, en Mouffe, La paradoja democrática, Barcelona, Gedisa, 2003, y El retorno de lo político, Barcelona, Paidós, 1999; o en Laclau, E., Emancipación y diferencia, Buenos Aires, Ariel, 1996.

3 Para un análisis de los matices diferentes entre globalización y mundialización, véase Marramao, G. Pasaje a occidente, Buenos Aires, Katz, 2006, cap. 1, 11-83.

4 «Cajón de sastre» la denomina Habermas en el artículo El valle de lágrimas de la globalización, Revista «Claves», n. ${ }^{\circ} 109$, enero 2001.

5 Marramao, G. Pasaje, op. cit., p. 53. 
lo social. La globalización se puede entender como ese carácter centrífugo del poder (político) desde el que se vertebra la crisis de la modernidad y del vínculo que enlazaba a los individuos con la comunidad, a la que venimos asistiendo desde hace unas décadas. La globalización implica también un cierto anonimato del poder (sólo cierto, pues muchos de los poderes que hoy imperan tienen nombre y apellido), y por ello, enfrentarse a esta situación se hace mucho más difícil pues el «enemigo» está oculto y es inaccesible (al menos aparentemente). El orden/desorden global tiene cada vez más la apariencia de orden espontáneo, de movimientos propios regidos por una nueva «mano invisible» que lo estructura y lo mantiene. Nos movemos con la impresión de que no podemos influir en él porque cualquier intervención global tendría peores consecuencias que las disfunciones que el orden actual genera ${ }^{6}$.

La derivación inmediata de esta situación es la falta de horizontes para un pensamiento realmente emancipador; en efecto, existe un convencimiento tácito de poco es lo que los humanos podemos hacer en común por cambiar este estado de cosas, pues el vínculo necesario que hace emerger la mínima solidaridad imprescindible para la acción en común parece que ha desaparecido en gran medida ${ }^{7}$. Este déficit de socialidad ${ }^{8}$ es el síntoma claro de una ruptura del vínculo social al que ahora asistimos y que configuraba el mundo moderno, al menos en la representación más o menos mítica de la modernidad con la que hemos convivido. Hasta ahora pensábamos nuestras vidas circunscritas a unos sistemas sociales que organizaban nuestras experiencias y proyectos vitales a través de mecanismos económicos, patrones culturales y estructuras institucionales en un marco nacional y cultural cierto y estable. Hoy día, aquello que solía coordinar al mismo nivel y dentro de una totalidad, ha sido separado y situado en niveles radicalmente diferentes. El orden en que se asentaba la modernidad se ha cortocircuitado al saltar por los aires los elementos básicos del mismo: el Estado-nación y los principios legitimadores de su soberanía, y generarse una autonomía de los sistemas económicos - y su expansión a nivel planetaria- que pasa por alto cualquier fin humano que no sea económicamente rentable, con unas consecuencias absolutamente nefastas a escala mundial ${ }^{9}$.

La literatura sobre esta problemática es ya ingente, pero aquí sólo vamos a ver su tratamiento en dos de los pensadores más emblemáticos e influyentes

6 Bauman, Zygmunt, En busca de la politica, México, FCE, 2002, p. 108.

7 Ya sólo nos encontramos con espectáculos de solidaridad a distinta escala ante hechos concretos o sucesos luctuosos, pero son situaciones momentáneas que cuando el acontecimiento que los provocó deja de ser noticia, de entrar en nuestros hogares, desaparece sin dejar rastro ni huella permanente.

${ }^{8}$ Concepto que Bauman usa en el sentido de Simmel, como un estar con los otros, al que añade la perspectiva moral de la responsabilidad respecto del otro, recogida de Lévinas. Ver Béjar, H., Identidades inciertas: Zygmunt Bauman, Barcelona, Herder, 2007, p. 170.

9 Bauman, Z., El desafío ético de la globalización, diario «El País», 20 de julio 2001. 
del panorama intelectual del momento: el alemán Jürgen Habermas (1929) y el polaco Zygmunt Bauman (1925). El primero tiene ya una amplia reputación en el ámbito intelectual que no es preciso subrayar; el segundo parece gozar de una fama tardía por mor de unas metáforas potentes para significar los males de las sociedades contemporáneas ${ }^{10}$. Pero, ¿son parangonables ambos pensadores? ${ }^{11}$. En la aproximación a sus obras hemos encontrado un - podríamos llamar - aliento común: la elaboración de una teoría social crítica del mundo contemporáneo con proyección en una posible acción política emancipadora. También participan del mismo punto de partida, la Teoría Crítica francfortiana, y de darle una dimensión normativa a sus estudios científicos, vinculando así sociología y filosofía. Quizá aquí acaben las semejanzas, porque la forma de abordar todos estos temas y el enfoque es bastante diferente. Por otra parte, el tratamiento que reciben en este texto no es equilibrado, y Bauman será tratado con más amplitud que Habermas, porque lo que interesa aquí es ver cómo el mismo punto de partida a la hora de abordar el problema de la crisis de lo político en época de globalización puede desembocar en dos perspectivas distintas, pero no contradictorias.

La actividad teórica de Habermas está lo suficientemente acreditada como para no insistir más en ella: su dedicación como profundo intérprete (crítico) del devenir de las sociedades occidentales al que ha conseguido darle un sentido desde categorías nuevas que dan razón de este mundo y de las posibles alternativas a sus distorsiones. Y siempre desde un compromiso con lo real, como conciencia moral de la sociedad. La obra de Zygmunt Bauman sea quizá menos conocida en nuestro ámbito cultural ${ }^{12}$, por lo que es preciso pararnos un poco más en ella. El autor polaco ha realizado una intensa labor en el campo de las ciencias sociales en continua interlocución con la filosofía con un lenguaje más cercano a la metáfora que a la categoría ${ }^{13}$, y fronterizo al ensayo más que al tratado. Como ha señalado una de las pocas comentaristas en castellano, su sociología no es sistemática, pero no deja de ser coheren-

10 Para algunos comentaristas, más que metáforas, lo que ha inventado Bauman han sido etiquetas que le han servido para hacerse un hueco en los best sellers filosóficos con unos ensayos triviales y repetitivos. Ver Gil Calvo, R., Retrato intelectual del ensayista líquido, diario «El País», 8 de agosto de 2007.

11 Siguiendo el ejemplo de Karl Löwith en su clásico sobre Max Weber y Karl Marx Barcelona, Gedisa, 2007, los elementos que se han de tener en cuenta a la hora de hacer la comparación son: 1) que ambos autores puedan medirse; 2) que lo comparable sea lo mismo pero diferente a la vez; 3) que, para nosotros, el correlato de ambas investigaciones comparativamente es diferente, pp. 32, 33. Intentaremos aplicar este método de análisis en este texto.

12 Para la recepción del pensamiento de Bauman ver Beilharz, P., La modernidad de Bauman, Rev. Anthropos, n. ${ }^{\circ}$ 206, Barcelona, 2005, pp. 72-89.

13 Bauman ha indicado que una de sus principales influencias ha sido J. L. Borges del que ha dicho que «aprendí de él mas que de ningún sociólogo sobre la condición humana». Entrevista con Juana Libedinsky en: http://www.forociudadano.com/ideas/BaumanImperioIndividuo.htm. 
te en la crítica a la Sociedad Perfecta y la necesidad de un proyecto moral para una sociedad que ha perdido las referencias morales y las instituciones duraderas ${ }^{14}$. Formado originariamente en el marxismo más ortodoxo de las Universidades polacas, pronto, dice «me convertí en un revisionista y rechacé la versión oficial del marxismo» ${ }^{15}$, aunque la crítica al capitalismo nunca deje de ser uno de los motivos centrales de su obra, no sólo en cuanto modelo de orden social sino también por el tipo de humanos que expele. Su tarea se ha centrado en detectar los rasgos más significativos que definen nuestra sociedad y en señalar los síntomas de sus patologías, desde una perspectiva que va más allá del dato empírico. La relevancia intelectual (y crítica) de su pensamiento se deriva de su capacidad para haber sabido interpretar las desigualdades y opresiones de la modernidad global que tienen que ver con «disposiciones de recursos materiales y no materiales, con las sobredeterminaciones del lugar y el constreñimiento de lo local sobre las biografías personales de la exclusión y la humillación» ${ }^{16}$.

El análisis que Bauman hace de las sociedades presentes le ha valido en muchas ocasiones el ser considerado como un pensador postmoderno; de hecho muchos de sus textos tienen este calificativo en su título ${ }^{17}$, sin embargo, él mismo rechaza ser asignado al discurso que se asocia con esta denominación ${ }^{18}$, aunque lo usara durante un tiempo porque era el término que mejor le encajaba cuando buscaba darle nombre a un conjunto de intuiciones sobre el devenir de la modernidad: «algo que expresara que, a pesar de las ambiciones modernas, la guerra contra el capricho humano y la contingencia histórica no se puede ganar» ${ }^{19}$. En múltiples ocasiones se ha quejado de que, una vez encuadrado en esta «clase parlante y exclusiva» (la postmodernidad intelectual), le ha sido muy difícil ser interpretado de otra manera y que se entendiera el sentido exacto que él le daba al término. Lo que sí que ha asumido como discurso propio ha sido la crítica de la modernidad y las «ambivalencias» ${ }^{20}$ que presenta, y el hecho de que nos encontramos en un momento distinto de la épo-

14 Béjar, H. Identidades inciertas, op. cit., p. 89.

15 Entrevista con Aida Eremarian para Clarin y The Guardian en http://www.clarin.com/diario/2007/05/04/sociedad/s-04101.htm.

16 Aguiluz Ibargüen, Maya, Impresiones de la pluralidad: las ventanas de Zygmunt Bauman, Revista Anthropos, n. ${ }^{\circ}$ 206, Barcelona, 2005, p. 52.

17 Entre otros, Intimations of Postmodernity (1992), Ética postmoderna (1993), Life in Fragments. Essays in Postmodern Morality (1995), La postmodernidad y sus descontentos (1997).

18 Para un análisis de la modernidad/postmodernidad de Bauman, ver Beilharz, P., La modernidad de Bauman, op. cit., pp. 75-76.

19 Entrevista con Helena Béjar, Zygmunt Bauman. Claroscuros de la modernidad, Revista Claves, n. ${ }^{\circ} 152$, mayo 2005, p. 48.

20 Concepto clave en la obra de Bauman para entender el lado oculto de una modernidad que se presenta como la búsqueda de orden y proyecto. Ver principalmente Pensando sociológicamente, Buenos Aires, Nueva Visión, 1990 y Modernidad y ambivalencia, Barcelona, Anthropos, 2005. 
ca moderna al que él denomina «modernidad líquida» para diferenciarla de una etapa anterior de la modernidad que se caracterizaría por la «solidez».

En esta crítica de la modernidad sí que coinciden Bauman y Habermas, aunque cada uno la enfoque desde perspectivas distintas. La vinculación originaria con la Teoría Crítica francfortiana ha hecho de Habermas un epígono consecuente de la misma, aunque superándola ampliamente; en Bauman queda más como hálito intelectual que como verdadero continuador. Pero en ambos sigue jugando un papel esencial la crítica como instrumento de emancipación. Aunque hoy día haya cambiado el sentido de la emancipación y la función de la crítica desde la época del Instituto para Investigación Social, la búsqueda de una «sociedad libre de dominación», permanece, para ambos, como el horizonte de la acción humana. La aproximación a una sociedad de individuos realmente autónomos en la que sus proyectos de vida sólo pueden encontrar la posibilidad de realización dentro de un proyecto de bienestar público, es el objetivo de estos filósofos desde un óptica «republicana» de la política (con matices, sobre todo en Bauman), con perfiles definidos en los dos.

\section{La crítica a la modernidad desde la globalización}

La crítica a la modernidad aparece unida indiscerniblemente a la misma modernidad, pero ¿cómo interpretan estos autores la modernidad desde el momento presente, desde el momento globalizador?

\section{La racionalidad comunicativa como racionalidad crítica. Habermas}

Frente a la interpretación de Weber, Horkheimer, o Adorno (o incluso Hannah Arendt), Habermas no va destacar de la modernidad sólo su carácter destructor, sino que encuentra en ella elementos de progreso moral, principalmente en el hecho de que la autoconciencia del sujeto y su estructura normativa debe estar justificada desde una racionalidad universalizadora. Toda normatividad reguladora debe pasar por el filtro de la deliberación racional intersubjetiva para poder alcanzar estatus de validez. Ese es el gran legado de la modernidad, para Habermas, que no la concibe sólo como un fenómeno histórico vinculado a un tiempo - la edad moderna - y a un espacio - occidentedeterminados (tal y como la entendía Weber), sino que la comprende como un modelo teórico de todo progreso moral, aplicable a cualquier momento y sociedad. La modernidad supone, para Habermas, el que las sociedades extraigan de sí mismas, al margen y contra las tradiciones instauradas, su propio autocercioramiento desde la relación interna que se da entre «praxis y racionalidad» explicitada en la acción comunicativa ${ }^{21}$.

\footnotetext{
${ }^{21}$ Habermas, J. El discurso filosófico de la modernidad, Madrid, Taurus, 1993, p. 100.
} 
El problema del dominio de la razón instrumental en el tiempo moderno no es el producto de un exceso de racionalidad, para Habermas, sino de un déficit de la misma. La razón, empero, tiene otras dimensiones que no han sido puestas en práctica y que son las que constituyen el arsenal con el que luchar contra el dominio de la racionalidad instrumental y que están insertas en las formas de comunicación humana dirigidas al entendimiento. De ahí, el famoso aserto habermasiano de la modernidad como un proyecto inconcluso, pues la modernidad no es sino una forma de pensar y actuar sobre la base de la racionalidad comunicativa. Desde aquí se puede entender la función de la crítica en Habermas. Él considera que el trabajo de la crítica es la de «afirmar la racionalidad comunicativa y su potencial de autorreflexión y autoexamen» ${ }^{22}$. Este desplazamiento hacia la racionalidad comunicativa va a marcar un giro en el camino de la crítica: desde las condiciones materiales de la existencia, a las condiciones formales de generación de consenso, y a las condiciones institucionales para políticas deliberativas, sin olvidar las primeras pues ellas son las que posibilitan un acceso real a las segundas para toda la ciudadanía.

Para entender la función liberalizadora que ejerce la racionalidad comunicativa en la modernidad, es preciso insertarla en la dimensión pragmática del lenguaje. Ésta es la que posibilita la comunicación y el entendimiento entre los hombres en sus relaciones diarias, en el «mundo de la vida» ${ }^{23}$, que es el que permite una forma de socialidad que vincula a los individuos en la comunidad pues se constituye en base a procesos de entendimiento. Habermas diferencia este espacio del «sistema» o «sistemas» donde rigen los principios del poder o la eficacia de la razón instrumental, y en el que la normatividad se presenta independiente de la voluntad de los individuos, como en las leyes del mercado. Como sabemos, para Habermas, el problema de la modernidad tardía ha sido la progresiva invasión de la racionalidad instrumental en los ámbitos en los que funciona la racionalidad comunicativa. Las relaciones de mercado salen de su ámbito propio y se instalan en el de la intersubjetividad y en el de la política (entendida más allá de la mera administración) haciéndole perder su sentido y su libertad. De todas formas, para Habermas, el mundo de la vida y las demandas racionales de legitimación no podrán ser completamente invadidas por los imperativos del poder y del dinero y siempre quedará la necesidad en los hombres de buscar ese «mejor argumento» universal que justifique la norma por medio de una política deliberativa ${ }^{24}$.

22 Borradori, Giovanna, La filosofía en la época del terror. Conversaciones con Habermas y Derrida, Madrid, Taurus, 2003, p. 110.

23 Expresión que Habermas extrae de La crisis de las ciencias europeas y la fenomenología trascendental de Husserl y que desarrolla, en su vinculación-crisis, con el «sistema» en su texto fundamental de Teoría de la acción comunicativa, Madrid, Taurus, 1987, t. I y II (especialmente en este último).

24 Habermas, J., Facticidad y validez, Madrid, Trotta, 1998, pp. 140-141. 


\section{De la crítica «itinerante» a la búsqueda de nuevas perspectivas. Bauman}

Para el autor polaco también la modernidad, al disolver las viejas relaciones del orden premoderno, deja el camino libre para el dominio de la economía y de la racionalidad instrumental en la configuración de un nuevo orden sólidamente asentado y absolutamente inmune a cualquier interferencia que no sea la de la lógica económica ${ }^{25}$. Para Bauman, el orden de la modernidad ${ }^{26}$ no ha degenerado sólo por la colonización del mundo sistémico en el mundo de la vida, como lo había interpretado Habermas ${ }^{27}$, sino por la disolución misma de los elementos que controlaban la libertad individual y permitían formas de comunidad en el orden moderno; ahora los nexos sociales se fragilizan, las comunidades se atomizan, y devienen «perchas» intercambiables: lo que él llama «desregulación», «liberalización», o «flexibilización» en todos los ámbitos.

Bauman se centra en los cambios producidos en el paradigma de la libertad moderna y sus consecuencias en la ruptura de relaciones entre las elecciones individuales y las acciones colectivas ${ }^{28}$ para explicar el tránsito de una primera modernidad «sólida» a la segunda caracterizada por su fluidez ${ }^{29}$ : ahora ya no podemos imaginar que nuestras elecciones personales puedan tener alguna repercusión en el ámbito colectivo y que ese ámbito pueda ser, por tanto, el lugar donde puedan encontrar acomodo y solución los problemas que generan las elecciones individuales. Y ello, insistimos, no por la invasión del sistema en el mundo de vida desde el que se idearían estas opciones de manera intersubjetiva, sino por la disolución, desregulación, del sistema mismo. Por decirlo de alguna manera, la modernidad ha fracasado por su propio éxito. Veamos cómo se produce esta paradoja.

El proceso de modernización en su afán de autoconstrucción autónoma de los individuos fue socavando todas las ataduras y limitaciones que constreñían a los habitantes premodernos: de su origen, de su condición social, de la dependencia teológica, del dominio heterónomo. El objetivo de la modernidad era la búsqueda de la autonomía de los ciudadanos y la realización de su

25 Es necesario citar aquí, aunque sólo sea tangencialmente, pues es imposible desarrollarlo, la relación «perversa» entre la lógica de la modernidad y el Holocausto que Bauman expone en Modernidad y Holocausto, Madrid, Sequitur, 1997.

26 El orden y su afán clasificatorio es el elemento definidor de la modernidad para Bauman, lo que hace caer en no pocas exageraciones y ambigüedades. Véase Béjar, H. Identidades, op. cit., pp. 80-81.

27 Bauman, Z., Modernidad líquida, México, FCE, 2006, p. 11.

28 Bauman, Z., Libertad, Buenos Aires, Losada, 2007.

29 El tránsito de una a otra no parece suficientemente justificado en Bauman, ni cronológicamente ni categorialmente, lo que genera, como en otros aspectos, una ambigüedad analítica propia de su obra. Aunque él mismo justifica su despreocupación por la metodología de la sociología más o menos oficial y clásica. Ver Bauman y Tester, La ambivalencia de la modernidad y otras conversaciones, Barcelona, Paidós, 2002, p. 4. 
libertad como sujetos. En esta tarea estaba implicado el individuo mismo y el autocercioramiento de su capacidad para tomar las riendas de su destino, a partir de su pensamiento y su acción. Ello le iba a conducir a la transformación en lo que uno es, a la individualización, la llama Bauman ${ }^{30}$. Sin embargo, la individualización, al igual que el proceso de racionalización que denunciaba Weber - y que es en el que se centra Habermas para hacer su crítica de la modernidad-, ha llevado a unos derroteros que no se esperaban: a la formación de una "sociedad de individuos» —al individualismo ${ }^{31}$ — como una exigencia del capitalismo en tanto que economía moderna que desestabiliza las formas comunitarias y las envía a un proceso de acumulación que si bien aumenta la producción de mercancías, destruye las formas de producción de orden social. Con ello, la autonomía se convierte en un mero reclamo publicitario y la libertad en libertad de mercado.

En las primeras fases de la modernización los sujetos contaban, para la autoconstrucción de sí mismos, con el apoyo del grupo de iguales, que en este caso eran las clases sociales (a las que se advenían por el «esfuerzo personal») que les abrían el abanico de posibilidades de elección. De esta manera, lo colectivo permitía el arraigo y la situación en el mundo de cada cual. Aunque, evidentemente, era la divisoria social la que establecía la mayor o menor libertad de elección.

Lo que ocurre en la «segunda modernidad», según Bauman, es la ruptura de esos lazos que vinculaban con la clase, con el grupo de iguales, para una finalidad $\mathrm{u}$ otra. En las sociedades contemporáneas, como «sociedades de individuos» ${ }^{32}$, no hay espacios que vinculen, o lugares comunes. Es cierto que los problemas siguen siendo comunes a todos y se derivan de la estructuración y jerarquización social, de las formas de vida sociales, pero ahora la responsabilidad de resolverlos se hace recaer absolutamente de lado de las personas tomadas de una en una ${ }^{33}$; cada individuo aparece, y se presenta a sí mismo, como culpable de su propia vida y de lo que ocurre en ella: si enferma, si no encuentra trabajo, si no tiene amigos, si triunfa o si fracasa. El triunfo de la libertad condena al sujeto a sí mismo. Y, sin embargo, al mismo tiempo, no se le dan los instrumentos para que pueda resolver esos problemas, pues esa libertad, en realidad, es ficticia: el sujeto no tiene capacidad para actuar.

Si la modernidad se había caracterizado por la construcción de un orden que permitiera un escenario fiable y duradero en el cual se pudieran desenvol-

30 Bauman, Z., Modernidad líquida, op. cit., p. 37.

31 Sobre el individualismo y su relación con el capitalismo y la libertad, ver Bauman, $L i$ bertad, op. cit., pp. 92 y ss.

32 Concepto que Bauman recoge de Norbert Elias, Modernidad líquida, op. cit., p. 35.

33 Al respecto ver también Richard Sennett, La corrosión del carácter: las consecuencias personales del trabajo en el nuevo capitalismo, Barcelona, Anagrama, 2000 al que Bauman alude con frecuencia. 
ver los proyectos de vida de cada cual que estaban sin hacer (de ahí que la libertad se erija en valor supremo), en «el período que vivimos ahora en esta parte del mundo» ${ }^{34}$, no parece haber ningún terreno firme sobre el que asentar los proyectos de vida, ni los esfuerzos individuales de construcción de identidades personales pueden eliminar los efectos de la desvinculación social. Ahora, dice Bauman, nos movemos en el terreno de la «incertidumbre», la desregulación, la flexibilización (principalmente en el ámbito laboral), o la nueva construcción del mundo desde la imagen y el simulacro ${ }^{35}$. Esta situación propaga «un sentimiento de la ineficacia social que impide la gestación de la solidaridad, $\mathrm{y}$, por tanto, la posibilidad de una movilización colectiva duradera» ${ }^{36}$.

¿Qué lugar le queda a la crítica en este modelo de realidad que vivimos?

Bauman señala que la crítica social actualmente se podría calificar de domesticada, amenazada, o en «itinerancia». Aparentemente nos encontramos en una situación en la que todos estamos comprometidos con la reflexión sobre nuestras condiciones de vida, en la que la exteriorización de la desafección con lo que hay se reconoce como una tarea inevitable de todos los miembros de la sociedad. Pero, rara vez, esa reflexión logra llegar a «los complejos mecanismos que conectan nuestros movimientos con sus efectos $\mathrm{y}$ que deciden sus resultados, y menos aun las condiciones que hacen que esos mecanismos jueguen con total libertad» ${ }^{37}$. El pensamiento crítico hoy no consigue penetrar, a lo que se ve, en las entrañas del ser social; sólo admite el juego del reproche y la negación siempre y cuando se mantenga dentro de los márgenes de lo permitido, mientras se mantenga inamovible el mismo movimiento que la sociedad contemporánea asume como posible. En este sentido, también para Bauman, el pensamiento y la acción críticos deben ocupar un lugar distinto al que tenían en la época de la Teoría Crítica. La labor de la crítica no puede desaparecer, e incluso «bajo ningún punto de vista hace de esa crítica algo superfluo» ${ }^{38}$, pero sí tiene que cambiar porque el mundo ha cambiado. La sociedad actual sigue siendo moderna en sus ansias de «creación destructiva», de hacer más y a cualquier precio, de avanzar en la producción y en la competitividad, pero el alcance del capital y de las exigencias emancipatorias ahora, más que nunca, tiene «dimensiones planetarias» ${ }^{39}$. Bajo estas condiciones, la modernidad que vivimos ahora se

34 Bauman, Z. La postmodernidad y sus descontentos, Madrid, Akal, 2001, p. 30. Esta es la forma que tiene el autor de calificar al período que en este libro llama «postmodernidad» y que luego sustituirá por «modernidad líquida» en textos posteriores por las razones que dábamos al principio de este trabajo.

35 Ibíd. pp. 34-36.

36 Béjar, H., Identidades inciertas, op. cit., p. 126.

37 Bauman, Z. Modernidad líquida, op. cit., p. 28.

38 Ibíd., p. 54.

39 Bauman, Z. Vida líquida, Barcelona, Paidós, 2006, p. 191. 
mueve entre dos polos que se oponen y complementan: la pérdida de la idea de progreso y la creencia en la posibilidad de una Sociedad Perfecta; de la misma manera funcionan la privatización y desregulación de las tareas y responsabilidades de la modernidad pues lo que antes se entendía como una labor del género humano en cuanto dotado de razón, ahora se ve como una actividad que cae del lado del individuo absolutamente ${ }^{40}$. $\mathrm{O}$ al menos eso es lo que venden las formas dominantes del marketing político y social. Desde la primera circunstancia, la historia parece haber perdido su telos ${ }^{41}$, desde la segunda, asistimos al triunfo de la individualización. De una forma u otra lo que parece perdido, según Bauman, es el sentido de una solidaridad de destino socialmente creado ${ }^{42}$.

En esta situación, la crítica no puede ser una pura búsqueda de la emancipación, porque aparentemente nos encontramos en el reino de la libertad; por ello, piensa Bauman, la crítica que Marcuse le hacía a la sociedad de consumo y a sus implicaciones con la libertad ha cambiado. En la interpretación que nuestro autor hace de Marcuse, considera que éste centró bien el concepto de libertad como el nudo sobre el que se construye la ideología de la modernidad pero en la época del capitalismo consumista, la gente ya no quiere hacerse cargo de las responsabilidades que implica la libertad y la autonomía, debido tanto al bienestar y prosperidad a la que se ha llegado como al ascenso de la mentalidad tecnocrática y los valores de productividad y apariencia de la cultura de masas. El triunfo de una cierta estabilidad, de gozar de los derechos que las generaciones anteriores no habían tenido, y el asentarse en las rutinas individualistas, es lo que hace que se vaya perdiendo la exigencia de libertad real para todos ${ }^{43}$.

La conclusión de Bauman es que en un mundo de desregulación e individualización, no tiene sentido hablarle al sujeto de emancipación en cuanto a desatarse de normas sociales opresoras porque precisamente lo que está deshecho es el vínculo social y las formas de regulación solidarias: «Lo único que se ha vuelto obsoleto es el significado asignado a la emancipación bajo condiciones hoy inexistentes, pero no la labor de emancipación en sí» ${ }^{44}$. Y, sin embargo, la individualización no ha conducido a una ausencia de normati-

40 Bauman, Z. Modernidad líquida, op. cit., p. 34.

41 Sobre la idea de progreso en Bauman, ver Beriain, J., La noción de progreso: una ilusión colectiva, Rev. Anthropos n. ${ }^{\circ}$ 206, Barcelona, 2005, p. 154.

42 Bauman, Z., La sociedad sitiada, Buenos Aires, FCE, p. 8.

43 Bauman, Z., Modernidad líquida, op. cit., p. 27.

44 Bauman, Z., Modernidad líquida, op. cit., p. 54. Helena Béjar interpreta esto de manera diametralmente opuesta a partir de la reproducción contraria de esta cita que ella traduce como «no es sólo el sentido atribuido a la emancipación bajo condiciones pasadas lo que resulta obsoleto sino la tarea misma de la emancipación», lo que le conduce a una interpretación más postmoderna del autor al negar en él la batalla por la emancipación que según la traducción de la versión castellana, que usamos aquí, sería aun tarea de la crítica, aunque ésta se entienda de manera distinta; ver Béjar, H., Identidades inciertas, op. cit., p. 97. 
vidad ni de control social ${ }^{45}$, sino al cambio de los espacios y los lugares en donde se cocina la normatividad reguladora: ahora no son los espacios institucionales, sino los nuevos espacios que marca el mercado. Las fuerzas del mercado - y el consumo como su correlato para la integración social y la reproducción sistémica - son las que perfilan la construcción del nuevo orden (desorden), pero estas fuerzas no están ellas mismas sujetas a ningún tipo de control, de donde se puede deducir que no existe ningún tipo de mecanismo, organismo colectivo, que se haga cargo de dar una cierta organización al sistema social. La única posible que funciona es la seducción por el consumo ${ }^{46}$.

Este desplazamiento es el que exige también el cambio de lugar de la crítica, pues ahora lo que hace falta es poner en evidencia las condiciones que hacen que esos mecanismos, por los que nos hacemos responsables de nuestras acciones y las conectamos con las de los demás, jueguen con total libertad, pero con una libertad consciente y responsable, no una libertad impuesta e individualizadora, como la que ha salido triunfante.

¿Dónde está, pues, el núcleo en el que se ha de centrar la crítica en época de globalización? Tanto Habermas como Bauman van a coincidir en señalar el desalojo del Estado como organizador de la sociedad por las fuerzas anónimas e «invisibles» de la economía y, en última instancia, del mercado, como factor nuclear para el desentrañamiento de los vacíos de la política y sus secuelas a otros niveles de las relaciones sociales, las formas de vida, y la construcción de las identidades, en época de globalización. También coinciden en colocar los lugares en los que se pone más de manifiesto esa crisis: la pérdida de autonomía y capacidad organizativa del Estado-Nación; el vaciamiento de la esfera pública y la ausencia de una mínima solidaridad social que lleva a los conflictos multiculturales o a la vuelta a un cierto tribalismo comunitarista.

Los dos ven, asimismo, que la forma de superar estos males pasa por la reconstrucción del vínculo político-social que sólo puede venir de la recuperación de un espacio público que restaure los nudos entre lo individual y lo colectivo. En lo que difieren es en la forma de recuperar el nexo social y los medios para alcanzarlo.

\section{La crisis del Estado y el vaciamiento de la esfera pública}

El progresivo desplazamiento del Estado en su tarea de organizador social por el empuje de las fuerzas globalizadoras, por una parte, y por la presión de las comunidades localistas - de consumo y de identidad-, por otra, ha ido socavando los principios de legitimación democrática del mismo (Habermas) e instituyendo un modelo de acción política que renuncia implícitamente a la

45 Bauman, Z., Libertad, op. cit., p. 153.

46 Bauman, Z., La postmodernidad y sus descontentos, op. cit., p. 54. 
transformación del mundo: la sustitución de la política de la emancipación por las políticas de la vida (Bauman).

Desde la centralidad que le concede a la esfera comunicativa en la formación de consensos en una política legítima, el último Habermas focaliza la legitimidad de la acción política desde la norma jurídica y la «producción legítima de derecho, que como hemos visto, está hermanada con la formación del poder comunicativo» ${ }^{47}$. El problema que surge en época de globalización para la legitimidad del Estado es su progresiva pérdida de autonomía respecto de los poderes globalizados: «un Estado que está progresivamente enredado en las interdependencias entre la economía global y la sociedad global ve reducida su autonomía, su capacidad de acción y su sustancia democrática» ${ }^{48}$. Para dar salida a este proceso deslegitimador, que pone en riesgo la pervivencia de la política misma, propone una política deliberativa que vaya más allá del marco nacional. Sólo se podrá «gobernar» el mercado global si se consigue crear una infraestructura política también de alcance global sin perder los procesos de legitimación democrática; esto es, crear unos espacios de deliberación pública de carácter transnacional que aun no existen ${ }^{49}$.

Aún asumiendo las mismas causas de la debilidad del Estado nacional que Habermas, Zygmunt Bauman incide sobre todo en lo que aquél consideraba el «mundo de vida» ${ }^{50} \mathrm{y}$, cómo desde la desintegración, la pérdida de certidumbre de éste, se va despedazando también el vínculo social «en la medida en que el Estado ya no preside la reproducción del orden sistémico, habiendo dejado ahora esta función en manos de las fuerzas del mercado, que, al estar desreguladas, ya no se hacen políticamente responsables de sus actos, el eje de gravedad del proceso de construcción del orden se desplaza, alejándose de las actividades de legislación/generalización/clasificación/ categorización» ${ }^{51}$.

La crisis del Estado-Nación, para Bauman, recae sobre todo en la vivencia de la seguridad de los individuos. El Estado ahora no puede proporcionar las redes de protección y estabilidad que daban el marco de referencia de los

${ }^{47}$ Habermas, J., Facticidad y validez, op. cit., p. 237.

48 Habermas, J., El valle de lágrimas de la globalización, op. cit., p. 5. Este texto sirve como base y será ampliado en el artículo «Euroescepticismo, Europa de los mercados o Europa de los ciudadanos (del mundo)» aparecido en Habermas, J., Tiempo de transiciones, Madrid, Trotta, 2004, pp. 91-110.

49 Habermas, Identidades nacionales y postnacionales, Madrid, Tecnos, 1988; Más allá del Estado nacional, Madrid, Trotta, 1997; La inclusión del otro, Barcelona, Paidós, 1999; El Occidente escindido, Madrid, Trotta, 2006.

50 Retomando quizá la posición privilegiada que el mundo intersubjetivo simbólicamente constituido tenía en Habermas, principalmente: Teoría de la acción comunicativa, vol. II, Madrid, Taurus, 1992, pp. 169-280; Teoría de la acción comunicativa: complementos y estudios previos, Madrid, Cátedra, 1989, pp. 489-507; Pensamiento postmetafísico, Madrid, Taurus, 1990, pp. 90-107; Textos y contextos, Barcelona, Ariel, 1996, pp. 59-73.

51 Bauman, Z., La postmodernidad y sus descontentos, op. cit., p. 53. 
proyectos vitales en la «modernidad sólida» y la época del Estado del Bienestar. Su fracaso no viene por la burocratización y reglamentación del mundo de vida, sino por su impotencia (como también indica Habermas) que deja al individuo aislado y solo ante sus propios miedos. Frente a las amenazas a la seguridad de los individuos y su desprotección, el Estado ahora - en la «modernidad líquida»— - sólo puede ofrecer una seguridad de carácter policial que aparece como la única seguridad posible ${ }^{52}$, creando un trampantojo de seguridad que escamotea las verdaderas causas: el dominio del capital, la flexibilidad laboral, la falta de solidaridad. Las auténticas causas de la inseguridad y la incertidumbre aparecen como absolutamente inaccesibles y lejanas, presentadas como imposibles de solucionar por los poderes locales. Lo único que podemos hacer es protegernos de los peligros inmediatos y reconocibles en una estrategia de «cabeza de turco» que no deja de ser perversa ${ }^{53}$.

Este menoscabo del poder de organización e intervención del Estado en los asuntos públicos no hace sino poner en evidencia la ausencia de una auténtica esfera pública, de un vaciamiento de su contenido que es perceptible y visible para nuestros dos autores.

\section{La pérdida de lo público}

Tanto Habermas como Bauman coinciden en la centralidad de la esfera pública no sólo para resolver los problemas públicos, sino para crear un auténtico vínculo social. En esto asumen la defensa de lo público como lugar de realización plenamente humana que ya reivindicara Hannah Arendt, así como la constatación de su decadencia actual, de su oscuridad. Lo que se está gestando es una sustracción del individuo de los asuntos públicos, su consideración como hombres masa más que como ciudadano, y por tanto la decadencia de la esfera pública ${ }^{54}$ y el dominio de lo privado. Para Arendt la oscuridad en la que se encuentra este espacio proviene de los propios males de la modernidad que ella diagnostica como «alineación del mundo», ${ }^{55}$ Desde ellos se puede detectar un vaciamiento escandaloso de la esfera pública y una aparente plenitud de la privada.

Habermas retoma el concepto de espacio público de Arendt y su constitución durante la Modernidad asumiendo los riesgos - detectados por la autora de La condición humana - que la despolitización, el vaciamiento del espacio público, tiene para el ejercicio legítimo del poder, pero él le da un sentido distinto pues tiene en cuenta a toda la ciudadanía más que sólo a aquellos indivi-

52 Que puede ejemplificarse en la fórmula del paso del modelo de «Estado social» y comunidad inclusiva a un Estado excluyente de «justicia criminal» o de control del crimen, Bauman, Z., Archipiélago de excepciones, Buenos Aires, Katz, 2008, p. 13.

53 Bauman, Z., En busca de la política, op. cit., p. 60.

54 Arendt, H., La condición humana, Barcelona, Paidós, 2005, p. 284.

55 Ibíd., p. 281. 
duos que muestran interés en los asuntos públicos. Desde los primeros textos, Historia y crítica de la opinión pública, hasta Facticidad y validez, Habermas considera, al contrario que la escritora alemana, que la esfera pública (burguesa) que se constituye en la modernidad es potencialmente democratizadora, pues se compone de personas privadas que razonan públicamente sobre temas de interés general permitiendo así el tránsito del individuo al ciudadano. Es cierto que pronto este espacio burgués va a poner de manifiesto sus limitaciones y contradicciones entre los ideales legitimadores de la burguesía, de carácter universalista, y la ocultación de los intereses y conflictos políticos y económicos ${ }^{56}$; además, la manipulación que sufre durante el «capitalismo tardío» desvirtúa sus planteamientos originales. Lo que conserva el potencial democratizador de este espacio es su carácter de publicidad - y en eso está con Arendt 57 - pues ella es el fundamento de la legitimación de las decisiones públicas en los sistemas liberal-democráticos. Para Habermas la ley sólo podrá justificarse, legitimarse, en el marco de deliberaciones públicas que pongan a prueba los argumentos desde los que se racionalizan las normas, y que deben estar sujetos a unas estrictas reglas formales (las reglas del discurso) ${ }^{58}$.

El «giro comunicativo» que Habermas imprime a la esfera pública incide también en su carácter emancipador, como portadora de intereses universalizables (moralizantes) que generen argumentos para la toma de decisiones políticas. Pero este carácter emancipador de la nueva esfera pública será efectivo si ésta es capaz de mantenerse inmune a la «colonización» de las reglas y métodos del sistema que ahogarían sus pretensiones universalistas bajo la presión de intereses particulares, pues aun el espacio público puede ser el lugar en el que «las sociedades altamente complejas pueden formar todavía una conciencia de sí mismas y tratar los problemas que son precisos para tener influencia política sobre sí mismas»» ${ }^{59}$.

Habermas, de todas formas, es consciente del carácter contrafáctico de su proposición, pero, precisamente por su naturaleza abstracta, puede ser un elemento regulador y normativo, como criterio para evaluar los problemas del mundo real desde la óptica de la distorsión comunicativa, en la que se tienen en cuenta también los factores de dominación social, de exclusión política, y

56 McCarthy, T., La teoría crítica de Jürgen Habermas, Madrid, Tecnos, 1998, pp. 439-441.

57 Para Arendt, el elemento definidor de la esfera pública es que es el lugar de «aparición» de las personas, en el que se hacen visibles, a través de la palabra y la acción, a sus otros semejantes, La condición humana, op. cit., p. 71.

58 Reglas que Habermas concreta, como respuesta a las objeciones de Frank Michelman, y aclara, respecto a lo presentado en Facticidad y validez, en el artículo «Estado de Derecho Democrático: ¿una unión paradójica de principios contradictorios?» en Tiempo de transiciones, op. cit., p. 156.

${ }^{59}$ Habermas, J., Verdad y justificación, Trotta, Madrid, 2002, p. 317. 
de manipulación de datos y de la información que influyen en la posibilidad/imposibilidad de una comunicación racional.

\section{La publicitación de lo privado y la privatización de lo público}

Zygmunt Bauman retoma la crítica arendtiana sobre la devaluación de la política en el mundo moderno y su progresiva «privatización». Si Habermas pone el acento en el componente comunicativo que implica el espacio público de Arendt y su potencial emancipador y humanizador, Bauman parece desplazar su análisis hacia la sociedad y lo económico ${ }^{60}$. A él lo que le interesa es analizar cómo el curso de la modernidad, en su devenir globalizador, ha ido socavando y desestructurando - vaciando de contenido- los espacios de participación y deliberación pública. En esto, creo, que coincidiría con los planteamientos habermasianos, aunque los conceptos de los que parte y que dan cuerpo a su teoría estarían muy alejados del autor alemán.

Para Bauman, los efectos que la globalización ha tenido en lo público han sido fundamentalmente los de su «privatización». De la misma manera que Hannah Arendt había visto muy incisivamente que las exigencias del capitalismo habían llevado a los individuos a centrarse en sus asuntos privados para poder responder a las demandas de mayor producción y consumo dejando la esfera pública al control de los expertos, Bauman detecta ahora una vuelta de tuerca en el proceso privatizador de los intereses, en la época del capital global, y una subversión de lo público y lo privado.

La modernidad había establecido como un valor fundante del sujeto el derecho a su privacidad ${ }^{61}$, a conservar sus asuntos privados en el seno de su intimidad, el derecho al secreto como expresión de un mundo propio que se descubre en uno mismo y que se reconoce como lo más auténtico ${ }^{62}$. En las últimas décadas asistimos a una trasposición del derecho a la privacidad en derecho a la publicidad, y el reconocimiento igualitario de la dignidad de todos se ha transformado en derecho a ser visto: «El modo de mercado consiste, por así decirlo, en construir el ser con el uso de imágenes. El ser se torna idéntico a los indicios visuales que otra gente puede ver y reconocer, con el significado que sea que deban transmitir» ${ }^{63}$. Para muchos de los habitantes de las sociedades actuales lo que uno es — su identidad - sólo adquiere sentido si es visto por otros, si se publicita de manera visible, como muestra de la

60 No se trata de explicar sociológicamente la política sino de buscar en ella un espacio regulativo de los cambios sociales. Ver Tapia Mealla, L., La búsqueda de la política, Rev. Anthropos, n. ${ }^{\circ}$ 206, Barcelona, 2005, p. 214.

61 No vamos a entrar ahora en el posible desplazamiento - encubrimiento- que este valor tenía del derecho a la propiedad de unos pocos.

${ }^{62}$ Bauman, Z., Libertad, op. cit., p. 129.

63 Ibíd., p. 158. 
personalidad propia y del reconocimiento de los demás. El reconocimiento público es un medio de construcción de identidades.

Evidentemente lo íntimo y lo público no son dos ámbitos completamente separados sino que muestran, como dice José Miguel Marinas, «sus pasadizos conectores no tan subterráneos» ${ }^{64}$ que nos indican que en lo propio de cada uno está emergiendo lo colectivo individualizado, y que lo público no puede realizarse con sentido si no tiene en cuenta lo que afecta a los individuos. Pero el problema, para Bauman, no está en la necesaria interconexión entre lo público y lo privado, sino precisamente en la desvirtuación de ambos términos. Una desvirtuación que no deja de ser interesada pues al convertirse lo privado en el «derecho a ser publicitado» se quiere presentar como un factor de liberación, como un ejercicio de libertad, lo que no deja de ser una expropiación (la del derecho a la privacidad) ${ }^{65}$.

La intervención en lo íntimo como una forma de control y disciplina, es algo que ya vieron autores desde Foucault, o más recientemente Jean-Claude Milner. Éste advierte sobre la significación de los mecanismos de control, los dispersos y los centralizados desde las instituciones, para la grafía de la domesticación generalizada de la libertad, entendiéndola como algo más que elección de productos de consumo ${ }^{66}$. Ahora bien, la publicitación de lo privado, como una forma de control más allá de los mecanismos panópticos de la «modernidad sólida», no podría darse si no se hubiera producido en paralelo un cambio de sentido de lo público, dice Bauman.

Lo público no podemos entenderlo ya como lo colectivo y común que aúna los intereses de los individuos que habitan un mismo espacio, el «mundo humano» del que hablaba Arendt, sino que por efecto de la individualización que ha subsumido a los sujetos de palabra y acción a su mundo cerrado y aislado, y por la pérdida del Estado como elemento organizador de la convivencia, ahora, lo público, ya sólo se concibe como el espacio donde se exhibe lo privado, donde esto despierta la curiosidad de la gente que se muestra a otros para su reconocimiento como entes privados. Esta privatización de lo público revierte en una deslocalización de la política, su traslado a aspectos que no parecen afectar a los ciudadanos, ávidos solamente de encontrar amparo y solución a sus cuitas particulares desde la imitación o comparación con los otros: «lo público ha sido vaciado de sus contenidos individuales y ya no tiene objetivos propios; no es más que un conglomerado de preocupaciones y problemas privados. Es un patchwork formado por la reunión de los reclamos individuales, que necesitan ayuda para dar sentido a las emociones y a

${ }^{64}$ Marinas, J.-M. «Lo público de lo íntimo, lo íntimo de lo público» en Marinas, J.-M. (coord.), «Lo íntimo y lo público. Una tensión de la cultura europea», Biblioteca Nueva, Madrid, 2005, p. 29.

65 Bauman, Z., En busca de la política, op. cit., p. 73.

66 Milner, Jean-Claude, La política de las cosas, Málaga, Miguel Gómez Ediciones, 2007. 
los estados de ánimo privados — hasta el momento desarticulados-, que piden, por un lado, instrucciones para expresar esas emociones y esos estados de ánimo en un lenguaje que los otros puedan entender, y, por otro, asesoramiento para enfrentar un caudal de experiencias difícil de afrontar individualmente» ${ }^{67}$. Lo que está ausente, según se deduce de esta cita, son propuestas colectivas para hacer frente colectivamente a los problemas individuales y la sustitución de la «política de los principios» asociada a los principios de igualdad, justicia y participación, por una «política de la vida» cuyo objetivo es que los ciudadanos disfruten estilos de vida, y expone la prioridad de los problemas privados en el terreno político ${ }^{68}$. Con esto, la que está amenazada es la esfera pública «que se vacía a toda velocidad debido a la deserción a ambos lados: la salida del "ciudadano interesado" y la huida del poder real a un territorio que, a pesar de todo lo que puedan hacer las instituciones democráticas existentes, sólo se puede describir como espacio sideral» ${ }^{69}$. El ciudadano ya no puede estar interesado sino en lo exclusivamente privado y desde lo privado, y el poder se ha vuelto anónimo y alejado de los posibles centros de deliberación democrática. Por ello, lo que se ha roto son los puentes entre la vida privada y la vida pública. El modelo de relación público/privado dominante ahora se articula sobre la base de un esquema comercial: se compran y venden servicios públicos; se genera una oferta de servicios, se regatea, se negocia.

Desde esto, la sociedad como tal no existe, no se genera vínculo social mancomunado. La individualización y la globalización han acabado con eso; el ciudadano político ha devenido exclusivamente «consumidor del mercado» ${ }^{70}$ y la libertad política «libertad negativa» (individual). Pero si la libertad política ya no parece posible - pues las exigencias del mercado y del consumo nos han apartado de las tareas comunes que no ve como accesibles ni tampoco como solución de sus propios problemas-, el triunfo de la libertad negativa también es aparente desde el momento que las elecciones personales están reguladas por las opciones del mercado que limitan su campo de actuación. Y sin embargo, Bauman, sigue pensando en la necesidad de un espacio público que posibilite la deliberación sobre el bien común como única salida para contrarrestar las tendencias individualizadoras de la sociedad de la modernidad en el momento presente.

La opción de Bauman es lo que él denomina la restitución del agora ${ }^{71}$ considerada como el espacio en el que se intercomunican lo público y lo pri-

${ }^{67}$ Bauman, Z., En busca de la política, op. cit., p. 74.

68 Béjar, H., Identidades, op. cit., p. 108.

69 Bauman, Z., La sociedad individualizada, Madrid, Cátedra, 2002, p. 117.

70 Bauman, Z., En busca de la política, op. cit., p. 87.

71 Concepto que Bauman extrae de Castoriadis, autor con el que se siente muy vinculado y deudor en muchos de sus conceptos, como el mismo reconoce en la entrevista con Keitth Tester, La ambivalencia de la modernidad y otras conversaciones, Barcelona, Paidós, 2002. 
vado, y, por tanto, el espacio político por antonomasia, porque en él se establece la agenda de opciones posibles en la sociedad y donde se negocia el contenido de la misma, y que hoy no parece tener lugar por la sensación generalizada de que no hay alternativa social posible. Un poco a la manera de Arendt, Bauman retoma los conceptos de la tradición griega — un tanto sublimados como en la autora alemana- que conceptulizan los espacios en los que discurre la «acción humana». Así, frente al oikos — que domina la privatización de lo público hoy_-, y la ecclesia, el espacio del poder institucional - cuya hegemonía conduce a los totalitarismos modernos ${ }^{72}$ - Bauman sitúa el agora cuyo papel principal era «asegurar un tráfico constante y fluido entre ambos campos» ${ }^{73}$.

Este espacio no lo proyecta Bauman como el de la libertad negativa ni el de la positiva en exclusividad, sino como aquél en el que se puede realizar otro tipo de libertad vinculada a la autonomía: la autonomía del individuo que está implicada en la autonomía de la sociedad. Retomando de nuevo otra idea de Castoriadis, considera que la autonomía de la sociedad sólo puede conseguirse mediante la autonomía de los individuos que deliberan libremente sobre el bien común ${ }^{74}$. Bauman vincula autonomía con incertidumbre y ésta con la democracia como régimen de reflexibilidad y autolimitación. En tanto que la autonomía mantiene como única certeza posible la de no estar seguros de haber alcanzado la sociedad perfecta, y la de romper con todas las certezas instituidas socialmente, siempre se está abierto a una nueva reinstitución de lo social, a su transformación y mejora, y eso es lo que abre el camino de la crítica y de la acción política. Ahora bien, la incertidumbre que supone la autonomía lleva también implícita la condición de la vulnerabilidad ${ }^{75}$ : el que todo proceso esté expuesto al cambio y a la interrupción de su acontecer por la aparición de nuevos procesos, o el cuestionamiento de las decisiones tomadas. La sociedad democrática (autónoma), como decía Castoriadis estaría en continua autoinstitución, como un proyecto abierto, pero esto — pensamos - la deja inerme ante sus propias condiciones de posibilidad, pues para no traicionar su identidad (en tránsito) se mueve en una incertidumbre «constituyente» y en un autocuestionamiento permanente por la realidad realmente existente de individuos socializados lo que no la hace factible ni real ${ }^{76}$, pero sí que podría servir como elemento

72 Bauman, Z., En busca de la política, op. cit., pp. 95-105.

73 Bauman-Tester, La ambivalencia de la modernidad, op. cit., p. 96.

74 Cabrera, Daniel H., Z. Bauman y C. Castoriadis: la teoría social como pensamiento crítico, Rev Anthropos, n. ${ }^{\circ}$ 206, op. cit., p. 129.

75 Que entronca claramente con el concepto de «fragilidad» de la acción que Hannah Arendt utiliza en su fenomenología de la misma en La condición humana, op. cit., pp. 216-219.

${ }^{76}$ En este sentido se podría reconocer la crítica que Habermas hace al proyecto de Castoriadis, El discurso filosófico de la modernidad, op. cit., p. 391. 
movilizador en una sociedad sometida a un «avance imparable de la insignificancia».

De todas formas, y al igual que ocurría con la acción comunicativa en Habermas, Bauman, también concibe el agora, como un desideratum, una idea regulativa desde la que rearticular los puentes rotos entre lo público y lo privado y restituir el auténtico sentido de la política como espacio de deliberación de lo que sea el bien común. Pero para ello ha de cesar en su despolitización y su privatización y en la renuncia a establecer en común las circunstancias por las que discurre la vida de las personas, de forma que vuelva a merecer la pena comprometerse individualmente por lo común. Restablecer el agora significa restablecer los vínculos porque sin ellos ni lo privado tiene posibilidades de elegir opciones libremente, ni lo público podrá ser percibido como «lo común y factible para la vida privada» ${ }^{77}$.

Las propuestas de nuestros autores para esta restitución del vínculo entre lo público y lo privado, para romper el círculo de la despolitización de lo público, discurren por caminos bien distintos, de acuerdo con sus planteamientos previos y la incidencia que pueden hacer en aspectos distintos. Habermas se decanta por la fundamentación de una «democracia deliberativa» y la formación de una cultura política que aúne las diferencias en sociedades complejas (lo que él denomina el «patriotismo constitucional»); Bauman, en socavar los principios en los que se asienta la «inseguridad» vital y social por la que discurre la sociedad actual y que es la «culpable» del vaciamiento y la huida de la esfera pública. Para renovar la seguridad perdida, Bauman propone, entre otras cosas, la generalización de un «ingreso básico» como camino para una remoralización de las formas de vida que, basándose en la ética del don de Marcel Mauss, permita un cambio de dirección en la corriente social, aunque, sin duda, aun lo percibamos como algo «distante y oblicuamente alcanzable». Pensar estas alternativas puede abrir posibilidades para recuperar la política en nuestros tiempos.

77 Bauman, Z., En busca de la política, op. cit., p. 117. 